\title{
A SAUDADE E OS SAUDOSISTAS - UMA REVISITAÇÃO DA POLÉMICA ENTRE ANTÓNIO SÉRGIO E TEIXEIRA DE PASCOAES
}

Onésimo Teotónio Almeida

Brown University

A questão da saudade é, nas letras portuguesas, mais do que um simples contencioso reduzido a um círculo restrito e supostamente inconseqüente de intelectuais e literatos. A intervenção de António Sérgio provocando uma famosa polêmica com Teixeira de Pascoaes revela desde logo a extensão e ramificações da problemática em causa. Uma revisitação dos oito textos que documentam a referida polêmica não apenas ajudará a fundamentar a afirmação acima, mas permitirá também elaborar um perfil ideológico ou, se quisermos, um esboço da mundividência dos dois pensadores, para além de nos permitir saborear uma boa polêmica portuguesa, que não deslizou para o insulto pessoal dentro daquela tradição de que Camilo Castelo Branco constituiu apogeu e paladino.

Quando o debate deflagrou era já bem conhecido do público erudito português o ideário de Teixeira de Pascoaes explanado em livros e publicações diversas, sobretudo na revista A Águia, órgão da Nova Renascença e promotor de um movimento intelectual e artístico destinado a fazer renascer o espírito português atolado numa decadência de três séculos já diagnosticada por Ribeiro da Silva, Alexandre Herculano, Antero de Quental e outros. António Sérgio, consciente do peso que, por sua vez, tinha também atingido na vida intelectual portuguesa, intervém com plena consciência do potencial efeito demolidor das suas palavras; Teixeira de Pascoaes, ao responder-lhe, não menos reconhece a seriedade do golpe desferido por Sérgio nos seu planos de construção de um ideário galvanizador do espírito nacional.

Sérgio age como cirurgião perspicaz que diagnostica o mal do seu doente e o leva à mesa das operações efetuando um corte fundo e certeiro no local 
infectado. Começa por apontar três pontos de vista que julga ser importante esclarecer: "1ํㅜ Que é realmente a saudade; $2^{\circ}$ Que representou ela nas nossas letras; 3ํㅡ Que poderia ela representar hoje" (SÉRGIO, 1988, p.97). ${ }^{1}$ Tenta de seguida responder ele próprio às questões enumeradas afirmando primeiro que "o que caracteriza a saudade é um certo quê de sentimento"; que o saudosismo propõe como definição de saudade a "lembrança de alguma cousa com desejo dela”; e, por fim, que Pascoaes propõe ser a saudade "a velha lembrança gerando um novo desejo”. Acrescenta, declarando-se na esteira de Almeida Garrett e de D. Francisco Manuel de Melo, que sendo a saudade uma nuança do sentimento, ela é "um rude fato de toda a animalidade" (SÉRGIO, 1988, p.98). Houve na literatura portuguesa muita saudade, mas isso deveu-se a condições sociais específicas, não sendo possível arbitrariamente eleger um determinado período da história em marco-padrão normativo. Sérgio põe a questão em termos lapidares:

Vocês teimam em ressuscitar o que não tem hoje condições de vida, obcecados pela idéia absurda de que certa maneira de certa época é uma maneira absoluta a que nos temos de sujeitar per omnia saecula saeculorum.

A saudade não era, como agora, premeditada; não foi um programa literário, uma combinação entre poetas, um mot d'ordre, uma mania, um tabuleta, um artifício. (...) Ninguém havia previamente combinado escrever assim. A saudade foi resultante de verdadeiros apartamentos. (SÉRGIO, 1988, p.98)

Enumera depois esses “apartamentos”, de entre os quais sobressaem os do período das descobertas. Em contrapartida, afirma ele, Pascoaes e os seus correligionários "fabricam a saudade artificialmente":

Vocês, meus amigos, criaturas alegres e sociáveis; pacatamente instalados na pátria amada, donde ninguém vos tira e onde vos amam todos; felicissimamente casados com as eleitas das vossas almas, ou em vias de

Texto originalmente publicado em António Sérgio, "Epístola aos saudosistas”, A Águia, vol. V, $2^{\mathrm{a}}$ série, $\mathrm{n}^{\mathrm{0}} 22$ (Outubro 1913), p. 96-113. Todas as citações dos textos dos dois intervenientes nesta polêmica serão retiradas de PASCOAES, 1988. 
matrimônio sem estorvos de maior, vocês proprietários uns, professores ou filhos-famílias outros, vivendo todos em vida sem grandes lutas nem paixões - de que raio têm saudades vocês todos, santo Deus? (SÉRGIO, 1988, p.99)

Para Sérgio, a saudade, ao invés do que dizem os saudosistas, está em desacordo com o espírito contemporâneo, pois a característica fundamental deste é "o mobilismo, o avanço, a tendência para diante, o desejo de ação e da vida ascensional”, enquanto a saudade é o contrário de tudo isso: “imobilismo, inércia, contemplação do passado, amor de cristalizar ou mumificar o que já foi” (SÉRGIO, 1988, p.100). Quem vive na saudade são os velhos e os desgraçados a quem a morte levou um ente querido. Por isso, em uns e outros se nota, acompanhando a saudade:

O horror do novo, o ódio ao movimento, um protesto contra a lei da mobilidade e do devir. Para o velho só merecem estimação as coisas do seu tempo - a juventude do seu tempo, as cantoras do seu tempo. Toda a variação foi uma queda e todo o imobilismo o indispõe. À mãe que vive na saudade do filho morto quantas vezes lhe ouvimos nós, mostrandonos um quarto ou gabinete: - "Está tudo exatamente como ele deixou. Não consenti que se movesse uma pena!”(SÉRGIO, 1988, p.100)

António Sérgio passa depois a uma nova questão: a da suposta intraducibilidade da palavra saudade. Para os saudosistas, esse fato é prova apodítica do carácter único do sentir português, mas Sérgio contra-argumenta não se tratar de nada exclusivamente nacional visto existirem em outras línguas termos equivalentes:

Muito ao contrário do que Pascoaes afirma, a palavra saudade é traduzível. Várias nações a representam por um termo especial: o galego tem soledades, soedades, saudades; o catalão, anyoransa, anyoramento; o italiano, desio, disio; o romeno, doru, ou dor; o sueco, saknad; o dinamarquês, savh; e o islandês, saknaor... (SÉRGIO, 1988, p.101)

De vez em quando, Sérgio não resiste a uma tirada de humor. Neste caso, remata assim a listagem do termo em outras línguas: 
Eles, porém, menos iluminados que nós outros, apesar de terem Ibsens, Ardigos, Höffdings, não se lembraram de construir a filosofia definitiva e surprema do anyoranismo, do desiismo, do doruísmo, do saknadismo, do savnismo, do saknaorismo.... Saknaorismo é catita! Meus queridos amigos, meus confrades, meus irmãos da renascença: é o que vocês são em islandês: saknaoristas! (SÉRGIO, 1988, p.101)

A terminar, volta a insistir no fato de os outros povos, possuindo na sua língua termos correlativos, terem além disso nas suas hostes uma série de nomes ilustres nas letras, no pensamento e nas ciências que os compatriotas dele e de Pascoaes não têm.

Teixeira de Pascoaes responde referindo-se aos termos da carta de Sérgio como “palavras de belicoso gênio galhofeiro" (PASCOAES, 1988, p.104) e contra-ataca indiretamente ad hominem afirmando conhecer alguns cães "bem mais capazes de sentirem a saudade que certos seres da espécie humana” (PASCOAES, 1988, p.105). É o momento em que a polêmica ameaça descambar para as tradicionais diatribes de ataque pessoal mútuo, mas curiosamente ela recupera rapidamente a moderação. Sérgio volta contudo a não resistir ao recurso, aqui e acolá, do humor, enquanto Pascoaes mantém sempre uma seriedade controlada e firme.

Pascoaes repete afirmações anteriores apoiando-se em autores estrangeiros que reconhecem a intraducibilidade da palavra portuguesa "saudade" e afirma que ela não é um conceito retrógrado ou paralisante. Como prova, apresenta o fato de Leonardo Coimbra a ter incorporado na sua filosofia criacionista. A dada altura, depois de repetir conceitos vagos em torno da definição de saudade, faz um reparo digno de registro por ser exemplificador do tipo de linguagem e raciocínio do Poeta:

Saudade é criação, perpétuo casamento fecundo da Lembrança com o Desejo, do Mal com o Bem, da Vida com a Morte... De resto, deixe-me dizerlhe: verdadeiro é tudo aquilo que o espírito concebe. Uma ideia, enquanto vive, é verdadeira. Ora nós, em Portugal, precisamos duma Verdade que seja a nossa razão de ser. Concorda? (PASCOAES, 1988, p.107)

É uma afirmação a evocar remotamente William James e a sua concepção pragmática de verdade. A esta passagem voltaremos no final deste trabalho. 
Ao castigar o tom de Sérgio em algumas das suas afirmações - Pascoaes diz que Sérgio "ama a chalaça" (PASCOAES, 1988, p.109) -, inicia-se entre os dois polemistas uma série de retratos mútuos. Algo caricaturais, eles permitem-nos estabelecer o perfil ideológico de cada um tal como o outro o vê. Assim, segundo Pascoaes, a Europa deu a Sérgio "cepticismo de mistura com eletricidade e carvão de pedra"; as suas "palavras modernistas são aviadoras; paira, portanto, sobre as coisas sem pousar" (PASCOAES, 1988, p.109). Prossegue acusando Sérgio de querer eliminar Camões quando "uma pátria necessita de se firmar constantemente na sua individualidade esculpida ao longo dos séculos" (PASCOAES, 1988, p.109-110). E repete proclamações como:

Resumindo: a saudade, como ela é hoje compreendida, não é mais do que a Saudade de Camões, do Povo, de Bernardim, a converter-se em consciência poética e filosófica. Representa, portanto, a raça lusitana na sua expressão subjetiva; é o seu íntimo perfil eterno e original. O povo português criou um sentimento susceptível de se tornar um alto critério orientador. (PASCOAES, 1988, p.110)

Em resposta, Sérgio não se contém. Desmanda-se mesmo um pouco. Diz ser Pascoaes o Aquiles enviado pelo saudosismo contra o seu detrator, mas não só: o seu "cabeça e chefe", "o próprio Agamêmnon, o rei dos reis", “o Mago, o Sacerdote, a Pitonisa” (SÉRGIO, 1988, p. 111). Declara ser esse carácter "noturnamente sacerdotal" de Pascoaes que o "aterroriza e conturba”, acrescentando depois que os comentários do seu interlocutor foram para ele "mais transcendentes e incompreensíveis", provindo de um espírito celeste que nada tem de comum com a natureza humana de Sérgio:

Pareceu-me que o meu amigo me refutava com uma Sonata de Beethoven. O seu pensar é encantador e feiticeiro. As suas palavras têm a doçura e a substância do vôo espiritual dum silfo; e se fosse possível conceber a claridade dum raio de lua, numa noite de nevoeiro místico, ao beijar o mais fundo do oceano -, eu diria que a sua alma é alguma coisa ainda de mais delicado e de mais tênue, de mais ultramundano e de mais puro. Com que sentido vislumbrar a subtilidade do seu verbo? Ele é, para o meu espírito, o perfume de uma rosa à distância de mil sonhos. (SÉRGIO, 1988, p. 111) 
Estão definitivamente extremados os campos: Pascoaes é um poeta-místico que argumenta com frases comovedoras, mobilizadoras até; Sérgio é analítico, tenta compreender as posições de Pascoaes, descobrir um argumento, mas encontra apenas afirmações que o transcendem - com fina ironia, deixa transparecer a sua convicção de serem mesmo completamente ininteligíveis. Pascoaes é “um poeta amabilíssimo" e ele, Sérgio, "um voluntaristaintelectualista, esculpido à custa da machadada num tronco já seco da antiga Helênia”, "admirador de Antero e Herculano", "todo atascado (...) no carvão de pedra da suja Europa” ${ }^{2}$. Sérgio termina o seu esboço de diferenciação entre ambos. Trata-se de "dois homens muito diferentes, substâncias incomunicáveis", como um rouxinol e um peixe: "V. é o rouxinol e eu o peixe”. (SÉRGIO, 1988, p. 112) Acrescenta que ainda pegou "na pena para desfiar os comentários" de Pascoaes mas desistiu. Sérgio sente-se demasiado apolíneo para suportar tanta osmose conceptual, tanta miscigenação isenta de dados históricos:

Criador de divindades com seu sangue imperituro, V. atira as suas frases humanamente inexplicáveis, quando afirma que o sangue lusitano é uma mistura em partes iguais de sangue ariano (?) e sangue semita, ou sangue romano e sangue semita, donde nasceu a Saudade; que o semita criou o culto do espírito e a Virgem dolorosa, e o pobre ária (coitadinho) só o culto da forma, a beleza objetiva; que ter alma e corpo é propriedade exclusiva de alguns dos nossos escritores; (...) que "a Saudade é a essência do Cosmos, o Fiat, o Verbo, a Alma do mundo” (SÉRGIO, 1988, p. 112-113).

E de novo sem controlar a veia satírica:

Veja, Pascoaes: V. deu ao mundo, não só a metafísica absoluta e definitiva, mas ainda no-la deu integral, completa, inteirinha: nada deixou por fazer à humanidade. Pois não é um absurdo que por esse mundo em gabinetes, universidades, bibliotecas - se continue a trabalhar, a discutir e a comentar? Que lhe resta a fazer à humanidade senão gastar dois tostões, e comprar um dos seus livros? (SÉRGIO, 1988, p. 115).

2 Alusão à caricatura que dele fizera Pascoaes. 
Sérgio confessa que ao ler Pascoaes dá consigo "num mundo fantástico e seráfico” onde “as montanhas são de mel, e os rios são de leite”, “os pássaros dão flor” e “das ginjeiras brotam homens, como das nações brotam ginjas” (SÉRGIO, 1988, p. 115). Avança depois uma explicação para tão desenraizada forma de encarar o mundo: o isolamento em que vive o Poeta. Por isso questiona a imagem que da Europa Pascoaes revela: "A Europa, o mundo civilizado da eletricidade, não é tão suja, bronca, céptica, encarvoada, como lhe parece em Amarante; e não é conosco (ai de nós!) que a Inglaterra manufatureira aprenderá o idealismo" (SÉRGIO, 1988, p. 116).

Avança de seguida para a questão do passado português. Segundo Sérgio, “o culto do passado é efeito e não causa das energias atuais”; na decadência há sempre o culto do passado - "onde houve idolatria do passado como no Portugal da decadência?” (SÉRGIO, 1988, p. 116). De imediato, a demonstrar como de fato se filia em Antero, reage contra "a carcaça do passado" em termos que evocam largamente o famoso texto das Causas da decadência dos povos peninsulares - "Num país onde a riqueza passageira destruiu os hábitos do trabalho e da economia, entorpeceu pela miséria, resultado infalível da prosperidade fictícia, a energia do coração, que faz lutar o homem com a adversidade e vencêla, de que serve estar de contínuo a pregar ao povo...”. Segue-se uma citação longa retirada de um Opúsculo de Pascoaes, em que o Poeta faz uma leitura no mínimo poética da história de Portugal. Após ela, Sérgio cita mesmo Antero: "Que é pois necessário para readquirirmos o nosso lugar na civilização? Quebrar resolutamente com o passado... A nossa fatalidade é a nossa história.” (Causas da decadência dos povos peninsulares) (SÉRGIO, 1988, p. 117).

A seguir, contempla a acusação de Pascoaes de que ele, Sérgio, recusa o passado, elemento importante para se criar algo, verdadeira fonte de energias. Em resposta, interroga de forma contundente, desarmando pela base a afirmação do Poeta: "Foi do passado de Portugal que o Portugal de D. Afonso Henriques arrancou as energias?” (SÉRGIO, 1988, p. 118). ${ }^{3}$

3 Sérgio reage contra as acusações de que teria tentado eliminar Camões e defende-se dizendo ter sido ele quem preveniu Pascoaes do "caimento" do épico "quando aparecesse o SuperDito, matematicamente anunciado”. (SÉRGIO, 1988, p. 118) Referia-se obviamente ao ensaio de Fernando Pessoa na mesma revista A Águia ("A Nova Poesia Portuguesa”) onde este último anunciava o aparecimento iminente do Supra-Camões. 
Volta de novo à Europa moderna e, especificamente, a países como a Inglaterra onde os operários se viram humanamente tratados após a evolução econômica, ao contrário dos países do Sul, onde continuam "sem dignidade e sem nobreza”. Acrescenta que o péssimo estado moral de Portugal é conseqüência “de uma economia parasitária” (SÉRGIO, 1988, p. 119). Sérgio devolve portanto a acusação a Pascoaes:

Para a defesa da minha pessoa farei uma pequena observação. Não é da Europa, meu amigo, que me vêm horas de cepticismo; é de Portugal e dos portugueses. Depois, sou céptico em relação a dadas coisas, mas não sou em relação a outras. Creio na ascensão da humanidade, na possível regeneração da minha pátria; sou céptico a respeito de muita idéia, como as virtudes da saudade e as profecias do Bandarra. (SÉRGIO, 1988, p. 120)

Nas restantes três intervenções da polêmica não há praticamente nenhuma novidade argumentativa, nem dado novo de qualquer ordem. Pascoaes lamenta que Sérgio viva "num mundo asfixiado entre as quatro paredes sem buracos do Positivismo", arvorando uma "atitude hirta e deserta perante a Vida” (PASCOAES, 1988, p.121). Prossegue reiterando aquilo que Sérgio apoda de "vacuidades poéticas", chegando a afirmar, a propósito dos gênios dos povos, que "há momentos em que um só homem é um Povo: Camões" (PASCOAES, 1988, p.125). Termina insistindo na imagem de um Sérgio exclusivamente preocupado com a economia (com "feroz paixão exclusivista”), as estatísticas, confessando mesmo que, quando dele se lembra, o visiona "mascarado de ferreiro, tentando forjar a golpes de martelo, uma pátria nova pelo derradeiro modelo de automóveis” (PASCOAES, 1988, p.126) - “o Ruído e a Velocidade estão na moda”. Adverte-o por isso, lembrando-lhe o que aconteceu ao rei Midas, de que "a criatura humana é mais alguma coisa que um armazém de comes e bebes”, não se devendo por isso limitar "a Realidade a quatro palmos de matéria bruta, e a eternidade de uma alma às horas do almoço e do jantar” (PASCOAES, 1988, p.127).

Sérgio responde-lhe de Nice, sem manifestar qualquer ofensa perante a pouco simpática caricatura que dele fizera Pascoaes. Associa a linguagem do poeta à retórica coimbrã, que produz cursos jurídicos e empregos em 
Secretarias do Estado, talvez mesmo em S. Bento. Acusa de simplista a visão de Pascoaes ("Sancta simplicitas!"; "síntese do vácuo"). Quanto à sua alegada empatia pelos povos do carvão, recorda ao seu interlocutor que os anglo-saxônicos, embora um povo de energia produtora, nem por isso deixam de ser o mais rico de poetas em toda a humanidade. Volta a classificar de "maravilhas do verbo" as considerações de Pascoaes e insiste no isolamento que se é, segundo este, "incombustível”, é também "comburente como todos os diabos, como ficou provado ao longo de três séculos da nossa história” (SÉRGIO, 1988, p.131).

Teixeira de Pascoaes contra-ataca revelando-se ofendido pela classificação de "maravilhas do Verbo" atribuída aos seus escritos, bem como por outras caricaturas que do seu pensamento Sérgio desenhara. Reconhecendo que Sérgio é "um dos mais lídimos caracteres e lúcidas inteligências do seu tempo", tenta rebater algumas afirmações históricas. Contrasta a sua própria visão da história portuguesa ("o génio português está na lógica da Renascença Italiana”) com a da Europa de Sérgio: enquanto os portugueses conquistavam a Índia para a vida mundial, os ingleses, franceses e holandeses de António Sérgio "conquistavam navios mercantes para exclusiva riqueza das suas pessoas”. (PASCOAES, 1988, p.140).

Na sua última intervenção, Sérgio apelida Pascoaes de "anjo sonhador”, e tenta repor a sua posição em matéria de história de Portugal e da Europa, evocando questões que entretanto se haviam infiltrado no debate: o bacharelismo português, as razões da prosperidade dos camponeses franceses e a representatividade italiana de uma figura como S. Francisco de Assis. Em jeito de despedida, escreve:

Eu reconheço que é por virtude, por bondade, por amor à sua terra que o meu amigo tudo inventa. Respeito e admiro a sua paixão; somente o quisera convencer de que erra supondo as invenções necessárias e prestimosas. Cumpre aceitar a realidade inteira, estudá-la carinhosamente sob todas as suas formas; de nada serve mutilá-la. (SÉRGIO, 1988, p.147)

E, quase a finalizar, indiciando mesmo ter chegado ao termo da sua participação na polêmica, como se resignado ao reconhecimento da impossibilidade do diálogo, ou pelo menos do carácter infrutífero do mesmo: “Ah! 
meu poeta, só agora compreendo o Evangelho de S. João: "No princípio era o Verbo, e o Verbo era Deus!” (SÉRGIO, 1988, p.147).

A confirmar que os dois homens argumentam a partir de campos opostos por funcionarem no interior de mundividências ${ }^{4}$ quase antagônicas, Pascoaes é peremptório na recarga: "Mais que para discutir, eu nasci para afirmar. Nem as grandes verdades se discutem: afirmam-se!” (PASCOAES, 1988, p.149) saída dogmática que lembra o famoso dito de alguém: num debate, se se quer saber quais são as convicções últimas de uma pessoa, contra as quais não existem argumentos, basta verificar quando ela começa a corar.

O resto da sua última intervenção é, no fundo, uma admissão de incapacidade de argumentar contra Sérgio. Nega ser rouxinol ou arcanjo, mas classifica o seu oponente de "mocho da ciência" e acrescenta, em irônica modéstia, que perante os seus "pios eruditos" “emudece":

Boquiaberto, sinto passar, por cima de mim, esse temporal de nomes, datas, citações. Depois, trêmulo ainda, observo-me, a ver se escapei, se pertenço ainda a este mundo.... Vejo que, uma vez mais, nada sofri.

Perdoe querido mestre, à minha pobre ignorância, tal arrojo e desabafo. Se ela encara assim, frente a frente, a grave sisudez da sua sapientíssima pessoa, é que é uma criança, como lisonjeiramente diz. Na verdade é uma criança, e eu gosto deste papel de menino entre os Doutores. A sabedoria tem os seus caprichos muitas vezes - e tem graça... Gosta, por exemplo, de aparecer disfarçada num sorriso infantil, às taciturnas frontes que o estudo macerou, embasbacando-as! (PASCOAES, 1988, p.149-150)

E, logo de seguida, esta tirada desarmante que deve ter feito Sérgio convencer-se definitivamente de que não valia a pena prosseguir:

Uma cantiga de Coimbra (...) afirma que há mais ciência num beijo de amor que nos livros dos doutores. Através da ária irreverente, meu caro amigo, transluz uma grande verdade! É que o beijo cria a vida, dilata a

\footnotetext{
4 E por isso muito mais do que simples divergências de leituras da história, como têm visto alguns críticos.
} 
criação, acende novas almas, para ver como elas foram feitas... Também há ingenuidade, infantilidade, nos sábios, meu caro António Sérgio...

Eu voto pela cantiga de Coimbra. (PASCOAES, 1988, p.150)

Sérgio, concede Pascoaes, poderá ser um erudito, homem da ciência, da lógica grega, da economia. Na parte final da sua intervenção, Pascoaes reafirma ainda outra vez as diferenças de fundo entre ambos: "é pelo sonho e não pela razão que o homem se destaca dos bichos” e ele, Pascoaes, quer “o exclusivo do sonho” (PASCOAES, 1988, p.151).

É difícil conceber-se dois campos mais extremados. Um diálogo de surdos assim não propicia qualquer avanço. Sérgio é herdeiro, descendente direto, de Aristóteles e da razão grega que sem negar o papel do coração, reconhece que as realidades têm os seus nomes e as idéias devem estar ligadas a outras por regras lógicas. Pascoaes é, em contrapartida, um poeta que às vezes escreve poesia em prosa, elaborando construções míticas e para-místicas que não se querem passadas por nenhum bisturi pois por definição escapam a qualquer análise.

Os dois polemistas conseguem uma relativa coibição e não se insultam. Não têm qualquer interesse nas visões do mundo um do outro, mas respeitam-se civilmente. Sérgio não vai tão longe quanto podia na sua argumentação. Poderia por exemplo ter concedido o benefício da dúvida à intraducibilidade da palavra "saudade", para demonstrar de seguida que isso não implica mais do que uma particularidade numa cultura, sendo que nunca essa particularidade pode, em jeito de sinédoque, tomada pelo todo - numa palavra, Pascoaes essencializa um particular. Mais ainda, poderia ter acrescentado não haver essências imutáveis nas culturas, posto que estas se transformam ao longo dos séculos, como aliás ele próprio ilustrou com casos históricos. Não é aqui todavia o lugar para fazer a crítica do saudosismo. ${ }^{5}$

\footnotetext{
Fi-la em "Filosofia portuguesa - alguns equívocos". Um argumento, por exemplo, que Sérgio não contempla é o fato de uma língua poder ter um termo intraduzível noutra e até ver esse terno adotado literalmente noutras línguas sem por isso implicar algo ontologicamente constitutivo da personalidade do povo que fala essa língua. A história das línguas está cheia de linguistic borrowings, empréstimos de termos e expressões. Veja-se ALMEIDA, 1985.
} 
Fernando Pessoa viu em Pascoaes uma "gravidez do Divino" e adotou várias facetas da sua visão ao elaborar o projeto da Mensagem. Uma delas foi a concepção pragmática da verdade: se a verdade pode ser muitas coisas, não há nada que nos proíba de escolher o que queremos que ela seja e lutar para que ela aconteça. ${ }^{6}$

É um conceito de verdade por sinal hoje muito em voga entre pósmodernistas, mas completamente alheio ao cartesiano espírito de Sérgio, que, além do mais, bem tentou rejeitar como desajustado a classificação de positivista que lhe foi atribuída. ${ }^{7}$ No código de Pascoaes, era-o simplesmente por a Razão ser positivista. Igualmente aqui, Pascoaes afirma e não sente necessidade, nem obrigação de demonstrar. Está naturalmente dentro da sua concepção de verdade.

Esta não foi, com efeito, uma polêmica à portuguesa. Nela entraram dois espíritos superiores. António Sérgio distinguiu sempre o poeta das idéias mítico-filosóficas que defendia e, ainda mais, da pessoa que as defendia. Pascoaes reciprocou. Trataram-se sempre com dignidade. Quando em 1951, quase quarenta anos após o debate aqui analisado, a Academia de Coimbra homenageou Teixeira de Pascoaes, sendo oferecido ao poeta um volume intitulado A Teixeira de Pascoaes, a Academia de Coimbra, Maio de 1951, reunindo poemas e estudos sobre o autor de Maranus. O organizador do volume, J. de Montezuma de Carvalho, convidou António Sérgio a participar e este acedeu prontamente (CARVALHO, 1979, p.13). Enviou um soneto assim introduzido:

Creio que não tenho competência alguma para falar de Teixeira de Pascoaes: e se acudo agora com estas linhas rápidas, cuja valia é zero, é

\footnotetext{
Sobre este assunto, veja-se ALMEIDA, 1987.

Qualquer pessoa minimamente conhecedora do pensamento sergiano aceitará que assim é de facto. Como mero exemplo dos estudiosos que isso têm reconhecido, refira-se aqui a afirmação de J. Oliveira Branco (1986, p.277): "Não sofre, a Sérgio, a mais leve sombra de dúvida que 'o homem, finalmente, se define em termos espirituais'. Este é um ponto determinante para todo o sergismo." Para os menos familiarizados com o pensamento Sergiano, bastará um breve olhar de relance pela antologia organizada por A. Campos Matos (1983), ou a colectânea de textos da Homenagem a António Sérgio (Lisboa: Academia das Ciências, 1976). Apesar de tudo, uma certa franja do pensamento português insiste na acusação de positivismo a Sérgio, como fez recentemente um jovem intelectual num artigo no Jornal de Letras.
} 
só para não faltar nesta grande homenagem tão justa, bendizendo o destino que me dá ansa fácil de desfazer um mal-entendido que já dura há anos. Com efeito, lá porque um dia levantei reparos a que se apresentasse como doutrina de todos nós (os membros da Renascença, colaboradores de A Águia) um nacionalismo estético-psicológico-político que era apenas dele e de poucos mais, criou-se essa lenda de ser eu adverso a um eloqüentíssimo poeta que sempre admirei e amei. (SÉRGIO, 1974, p.91)

Seguia-se o soneto:

\section{Ao Teixeira de Pascoaes}

As pessoas são nada, e as cousas tudo;

Ah, se o pensaste assim, e se o disseste, É que, infundindo-lhe alma, às cousas deste

Um coração represo, arfante e mudo!

O penumbroso monte, o tronco rudo,

Vivem na névoa humana em que os puseste:

Tornaste irmão ansioso o vento agreste

E carinhosa a relva em seu veludo.

Bendito o canto teu, porque desperta

Essa visão de uma alma já liberta

Das cadeias da luta e da miséria.

E ao Paraíso ao cabo regressada, - Porque viu, ao fulgor da Vida Etérea, Que as pessoas são tudo, e as cousas nada!

Por que uma reação destas? Haviam decorrido muitos anos, é certo. A Nova Renascença não florescera muito, embora alimentasse ainda uma forte vertente salazarista. Mas até Fernando Pessoa, que inicialmente se associara ao movimento, desaparecera também sem que a sua Mensagem tivesse então provocado qualquer impacto para além de um prêmio do SNI. Entretanto, a intelectualidade portuguesa rodeava Sérgio, e nos seus ensinamentos bebia inspiração para a almejada transformação da mentali- 
dade do país. Por outro lado, movimentos ideológicos de conseqüências mais profundas começavam a entrar em cena. Se, porém, não custava a Sérgio ser magnânimo, não era ainda assim obrigatório que o fosse.

As verdadeiras razões da sua participação na homenagem são-nos, todavia, fornecidas pelo próprio António Sérgio em curtos mas lapidares parágrafos precedendo o seu soneto. Sérgio considera que o maior defeito do nacionalismo estético de Pascoaes é ser muito injusto para o próprio poeta, por esbater nele o que há de mais "valioso e intrínseco", algo mesmo excepcional na poesia portuguesa, profundamente marcada pela melancolia tendencialmente deletéria e desmotivadora. Em contra-corrente, Pascoaes é "o mais romântico de todos os escritores portugueses na modalidade mais nórdica que o alto romantismo assumiu” (SÉRGIO, 1974, p.93). Além disso, a sua poesia é "um protesto contra o Deus demiúrgico, contra a Divindade criadora do Testamento Antigo". "As dores de quem sente, Pascoaes transfere-as por imaginação para o conjunto das coisas que espontaneamente humaniza” (SÉRGIO, 1974, p.92-93), o que é também invulgar na nossa lírica. E acrescenta:

Em tal grau se dá nele a transmigração para as coisas, que nos poemas mais íntimos, de mais autêntico lirismo, ele se esquece dos homens como seres individuais e distintos, como mais próximos do poeta, reduzindo-os a elementos do grande ambiente físico, que é a personagem capital da sua obra poética; e de aí o aparecimento deste verso estranho, à primeira vista inumano: “as pessoas são nada, e as coisas tudo" ( $A s$ Sombras. P. 84). (SÉRGIO, 1974, p.93)

Foi, acrescenta Sérgio, a leitura desse verso que lhe inspirou o improvisado soneto de homenagem ao Poeta, seu antigo co-polemista. O supostamente positivista Sérgio mais uma vez a revelar a sua idiossincrásica luminosidade, separando clarividentemente o analisável à luz da razão, do pertencente a esferas esconsas do espírito humano, e sempre conservando a serenidade e o discernimento necessários para reconhecer a diferença. ${ }^{8}$

8 Os interessados noutros pontos de vista sobre esta problemática, bem como em elementos históricos que ajudem a contextualizar esta polémica, encontrarão muito úteis elementos nos dois volumes especiais da Revista de História das Ideias (do Instituto de História das Ideias 


\section{BIBLIOGRAFIA}

ALMEIDA, Onésimo Teotónio. Filosofia portuguesa - alguns equívocos, Cultura - História e Filosofia, vol. IV (1985), p. 219-255.

ALMEIDA, Onésimo Teotónio. Mensagem - uma tentativa de reinterpretação Angra do Heroísmo: Secretaria Regional da Educação e Cultura, 1987.

BRANCO, J. Oliveira. O humanismo crítico de António Sérgio. Análise dos seus vectores filosóficos. Coimbra: Gráfica de Coimbra - Publicações do ISET, 1986.

CARVALHO, J. de Montezuma de. António Sérgio. A obra e o homem. Lisboa: Arcádia, 1979.

MATOS, A. Campos (org.). Diálogo com António Sérgio. Lisboa: Arquê, 1983.

PASCOAES, Teixeira de, SÉRGIO, António. A polêmica com António Sergio. In: PASCOAES,

Teixeira de. A Saudade e o Saudosismo (dispersos e opúsculos). Lisboa: Assírio \& Alvim, 1988. p.97-154.

SÉRGIO, António. Ensaios. Tomo VII. Lisboa: Livraria Sá da (Footnotes)

da Universidade de Coimbra) dedicados a António Sérgio e coordenados por Fernando Catroga e Amadeu Carvalho Homem ( $\mathrm{n}^{\mathrm{o}}$ 5, 1983), particularmente em Fernando Farelo Lopes, "Antonio Sérgio na "Renascença Portuguesa” (p. 403-425); Olga de Freitas da Cunha Ferreira, "António Sérgio e os Integralistas" (p. 427-469); e Jorge Borges de Macedo, "Significado e evolução das polémicas de António Sérgio", (p.471-531). 